\title{
Proposal for tutorial: Resilience in carrier Ethernet transport
}

\author{
Berger, Michael Stübert; Wessing, Henrik; Ruepp, Sarah Renée
}

Published in:

7th International Workshop on Design of Reliable Communication Networks, 2009. DRCN 2009.

Link to article, DOI:

10.1109/DRCN.2009.5339982

Publication date:

2009

Document Version

Publisher's PDF, also known as Version of record

Link back to DTU Orbit

Citation (APA):

Berger, M. S., Wessing, H., \& Ruepp, S. R. (2009). Proposal for tutorial: Resilience in carrier Ethernet transport. In 7th International Workshop on Design of Reliable Communication Networks, 2009. DRCN 2009. (pp. 381384). IEEE. https://doi.org/10.1109/DRCN.2009.5339982

\section{General rights}

Copyright and moral rights for the publications made accessible in the public portal are retained by the authors and/or other copyright owners and it is a condition of accessing publications that users recognise and abide by the legal requirements associated with these rights.

- Users may download and print one copy of any publication from the public portal for the purpose of private study or research.

- You may not further distribute the material or use it for any profit-making activity or commercial gain

- You may freely distribute the URL identifying the publication in the public portal 
Proposal for Tutorial: Resilience in Carrier Ethernet Transport

\begin{abstract}
:
This tutorial addresses how Carrier Ethernet technologies can be used in the transport network to provide resilience to the packet layer. Carrier Ethernet networks based on PBB-TE and T-MPLS/MPLS-TP are strong candidates for reliable transport of triple-play services. These technologies offer Operation, Administration and Management (OAM) functionalities and support for Quality of Service (QoS), required to obtain carrier grade quality. This tutorial provides an overview of the current level of standardization followed by an exhaustive survey of Carrier Ethernet reliability. A number of enhancements are still required to make Carrier Ethernet ready for large scale deployments of reliable point-to-multipoint services. The tutorial highlights the necessary enhancements and shows possible solutions and directions towards reliable multicast. Explicit focus is on OAM for multicast, where the signalling to identify faults is described. Finally, best practises from a Danish National project are shown.
\end{abstract}

\title{
Presenters: Michael S. Berger, Henrik Wessing, Sarah Ruepp, DTU Fotonik, Technical University of Denmark
}

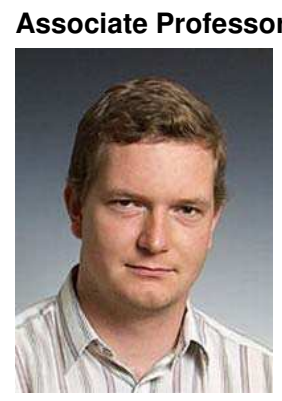

\section{Michael S. Berger}

Michael S. Berger is currently Associate Professor at DTU Fotonik within the area of switching and network node design. In his PhD thesis "Architectures of Electro-Optical Packet Switched Networks", focus was on network- and node architecture for future packet switched networks. During his PhD study, he participated in the IST project DAVID - a project on network and node architectures for optical packet networks. His main contributions were on concept definition, traffic performance and benchmarking. He has been involved in the IST project ESTA (Ethernet at 10 Gigabit and Above), where he examined node and network architectures for very high speed Ethernet switching. Currently, he is involved in COMANCHE and WP leader in the IST projects GIBON (on 100 Gigabit Ethernet), and he is leading a project on next generation IP networks for IPTV partly funded by the Danish National Advanced Technology Foundation. He holds a position as board member of the Danish Telecommunication Society IDA-TTS.

\section{Associate Professor Henrik Wessing}

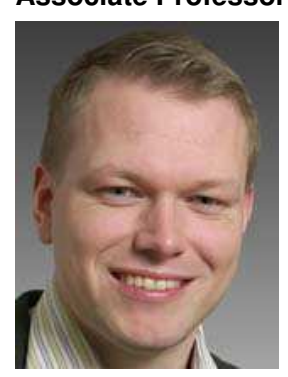

After completing the Master degree, Henrik Wessing worked as research assistant in the Networking Competence Area at Research Center COM (now DTU Fotonik), and in 2001 he began to pursuit his $\mathrm{PhD}$ studies on electronic control of optical infrastructures and components. In this project, control-electronics for controlling devices and network architectures were specified and implemented in FPGAs. In the European IST project DAVID he participated in the development of the experimental demonstrator and, as WP leader in the IST-MUPBED, he coordinated the activities integrating applications with the optical infrastructure. In addition he developed FPGA based control electronics for controlling 10 Gigabit links for a major industrial partner. After completing his Ph.D., Henrik Wessing continued at COM•DTU, now DTU Fotonik, with responsibility for the coordination, maintenance and development of research activities related to the experimental platform. Currently he is also involved in the European ICT project ALPHA coordinating the DTU activities and in the HIPT project as WP leader for demonstration activities.

\section{Assistant Professor Sarah Ruepp}

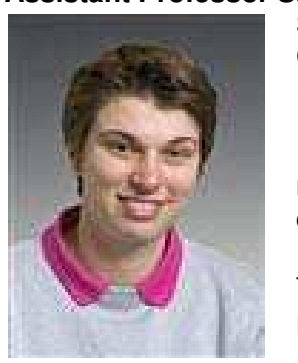

Sarah Ruepp obtained a B. Sc. in Electronic and Computer Engineering from the Engineering College of Copenhagen in 2002, and a M.Sc. in Telecommunications from the Technical University of Denmark in 2004. In 2008, she received a PhD degree on the topic of "Dynamic Protection of Optical Networks" at the Networks Area, DTU Fotonik, Technical University of Denmark. She is currently holding an assistant professor position at the same institution. Her research interests include topics related to designing, controlling and modeling of reliable communication networks. Sarah is currently involved in the HIPT project on reliable Carrier Ethernet transport and she is leading the project "The Road to 100 Gigabit Ethernet", both funded by the Danish Advanced Technology Foundation.

$\mathbf{r}$ 


\title{
DRCN Tutorial Proposal: Reliable Carrier Ethernet Transport.
}

\author{
Presenters: Michael S. Berger, Henrik Wessing, Sarah Ruepp, \\ DTU Fotonik, \\ Technical University of Denmark
}

The path towards profitable operation of networks today is paved with emerging premium services with strict requirements to bandwidth, delay, packet loss and resilience. Examples are IPTV, Video on Demand (VoD), Videoconferencing and telemedicine. They all uses IP on the packet layer but they demand reliable underlying transport networks for proper Quality of Experience (QoE). In a telemedicine video streaming application, where a doctor with special expertise remotely acts as second opinion, highly reliable transport is obviously required. In addition, such a service has strict delay bounds, which demands fast recovery.

Other services like IPTV require multicast transport, and the ability to quickly identify and isolate a faulty situation in a complex multicast architecture can make the difference between profitable or non-profitable operation.

The demand for high quality reliable services further increases the complexity, when the range of the services extends the local network and multi-domain issues arise. Hence, a standardised connection monitoring is required to proactively avoid most errors and to react swiftly to the remaining.

Therefore telecom carriers have spent more than 10 years developing a Next Generation Network concept that will allow them to replace the classical transport network to provide high quality packet transfer. Carrier Ethernet technologies address these challenges by adding transport functionalities including resilience to a packet based network infrastructure.

Ethernet as a transport technology has, up to now, lacked the features such as network layer architecture, customer separation and manageability that carriers require for wide-scale deployment. However, with the advent of PBB-TE and T-MPLS, it is now possible to use Ethernet as a transport technology, making the use of Ethernet as a convergence layer for Next Generation Networks a distinct possibility. Triple Play services, in particular IPTV, are expected to be a main driver for carrier Ethernet, however, a number of challenges must be addressed including enhanced OAM functions and survivability. This tutorial provides an overview of PBB-TE and TMPLS/MPLS-TP and demonstrates how resilient services can be realised in the framework of Carrier Ethernet. Furthermore, the challenges above are discussed and the current level of standardisation is outlined with focus OAM mechanisms and protection: Figure 1 shows the standardisation initiatives for T-MPLS with focus on G.8113 (Requirements for OAM functions in T-MPLS based networks) and G.8114 (Operation and maintenance mechanism for T-MPLS layer networks). Furthermore, T-MPLS defines its protection capability using ITU-T's Recommendations G.8131/Y.1382 (T-MPLS linear protection switching with 1+1, 1:1 and 1:N options) and G.8132/Y.1383 (T-MPLS ring protection switching). 


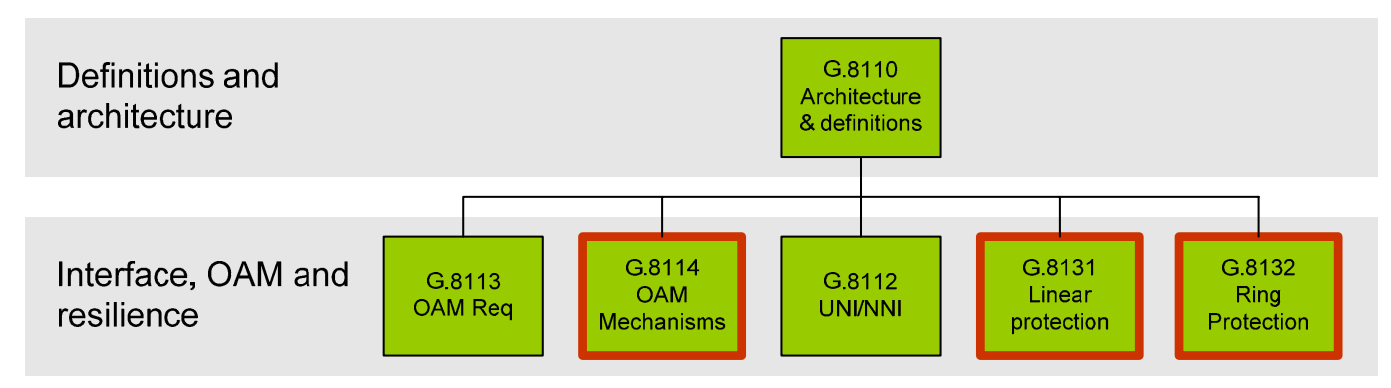

Figure 1 OAM and protection for T-MPLS/MPLS-TP

IEEE 802.1ag Connectivity Fault Management (CFM) has been recently developed to address the lack of end-to-end OAM in traditional Ethernet networks. It is closely aligned with the ITU's Y.1731 Recommendation (which also defines Performance Monitoring functions). Key functions such as loopback at specific MACs, linktrace to identify network paths and continuity check are defined. This standard and as shown in Figure 2 also ITU-T G.8031 (Ethernet Linear Protection) and G.8032 Ethernet Ring Protection forms the basis for PBB-TE fault management. Future trends in reliable Carrier Ethernet transport will also be discussed and the challenges in relation to reliable transport of point-to multipoint services will be outlined.

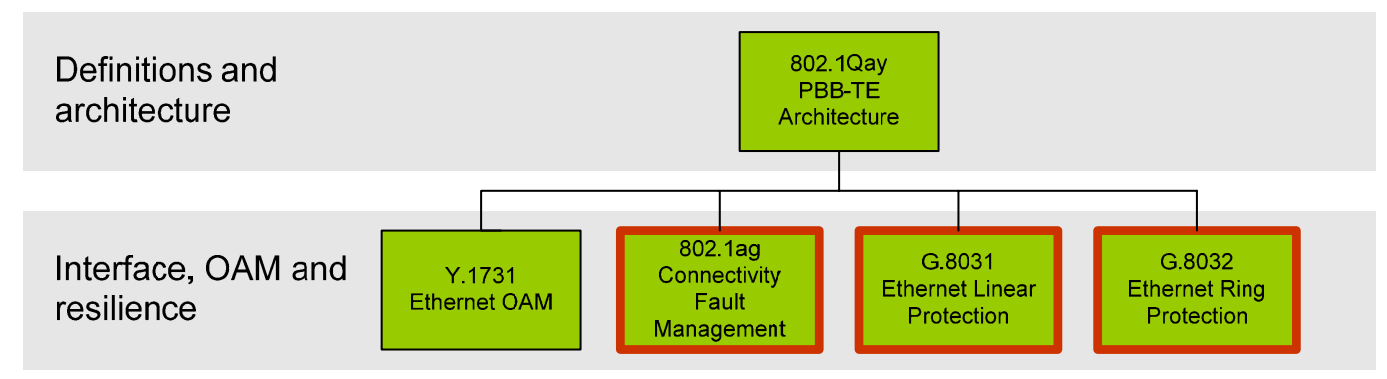

Figure 2 OAM and protection for PBB-TE

This tutorial will put special focus on resilient architectures and fault management in Carrier Ethernet transport networks. We outline the different failures that can occur in Carrier Ethernet networks and which challenges the different failure types (both hard and soft) pose on successful recovery. Following the recovery cycle, we detail how OAM (Operation and Management) messages can be used not only for failure detection, but also for failure notification. We go through the most relevant standards in the field as illustrated in Figure 1 and Figure 2, and we then show how OAM functions can be applied both in single and multi domain scenarios.

To repair the detected failure, we detail the recovery mechanisms applied in different topologies and specify the various choices for different services. In particular, we will look at how we can make point-to-multipoint services (e.g. IPTV) reliable by using appropriate and scalable fault detection and recovery mechanisms. Multicasting is the best choice for providing broadcast IPTV to a large user community. While Carrier Ethernet unicast service recovery has been already standardized, multicast service resiliency is a new hot topic and an emerging field of research. We outline the ongoing standardization approaches and show some examples of our own research in the field of multicast resilience. We outline the challenges for providing reliable multicast services and examine the failure types that can affect the IPTV service. In addition to physical failures (e.g. link cuts), the multicast service may suffer form 
failures in the actual multicast tree, corrupt OAM functionality and failure to comply with QoS (Quality of Service) requirements. We address these failure types and show which recovery mechanisms can be applied to successfully recover the service. Since Carrier Ethernet services are generally provided in the metro network area, which are traditionally built on interconnected rings based on SDH/SONET legacy, we show how Carrier Ethernet resilience functions can be applied on an interconnected ring structure in both a single and a multi domain scenario. We also present some of our research results and outline future trends in the field of Carrier Ethernet resilience.

The above described architectures are implemented as part of a Danish Advanced Technology Foundation funded project named HIPT. In the project a Carrier Ethernet infrastructure is built and used to provide reliable triple play services through transport networks. We conclude the tutorial with illustrative examples from the implementation and the related experiments. 